\title{
Importance of HPV Genotyping for the Screening, Therapy and Management of Cervical Neoplasias
}

\author{
Die Bedeutung der HPV-Genotypisierung für Screening, \\ Therapie und Management der zervikalen Neoplasien
}

Authors

Affiliation
M. Jentschke, P. Soergel, P. Hillemanns

Department of Gynaecology and Obstetrics, Hannover Medical School, Hannover

\section{Key words}

- cervical cancer

- cervical interepithelial neoplasia (CIN)

- human papillomavirus

Schlüsselwörter

- Zervixkarzinom

- Zervixpräkanzerose

- humane Papillomviren

\begin{abstract}
$\nabla$

In the last decade, the detection of human papillomaviruses (HPV) has become increasingly important in cervical cancer screening and the treatment of cancer precursors. HPV screening is recommended for the further evaluation of abnormal Pap tests or during follow-up after treating precancerous lesions. Several randomised controlled studies have shown that screening for cervical cancer using HPV detection can be more effective than cytology alone. Genotyping of different high-risk HPV (hrHPV) types obtained from smear tests has not yet gained widespread acceptance in clinical practice. However, significant differences have been noted in the oncogenicity of hrHPV genotypes. HPV 16 is by far the most common and oncogenic genotype. Genotyping of hrHPV could be helpful for the risk stratification of HPV-positive women.
\end{abstract}

\section{received $\quad 13.1 .2012$ \\ revised 23.4.2012 \\ accepted $\quad 4.5 .2012$}

Bibliography

Dol http://dx.doi.org/ 10.1055/s-0032-1314959

Geburtsh Frauenheilk 2012; 72:

507-512 @ Georg Thieme

Verlag KG Stuttgart · New York .

ISSN 0016-5751

\section{Correspondence}

\section{Dr. Matthias Jentschke}

Hannover Medical School Department of Gynaecology and Obstetrics

Carl-Neuberg-Straße 1

30625 Hannover

Jentschke.Matthias@

mh-hannover.de

\section{Introduction}

$\nabla$

The role of HPV detection in cervical cancer screening is still discussed controversially in Germany. One of the two main topics of last year's EUROGIN (European Research Organisation on Genital Infection and Neoplasia) conference, held in Lisbon in May 2011, was - in addition to HPV vaccination - the importance of HPV detection. The four-day conference focused less on the question whether HPV testing should be carried out as part of cancer screening. Many of the papers focused instead on the possibility of a more differentiated assessment of HPV infection based on the confirmation of individual high-risk HPV genotypes (hrHPV).

\section{Zusammenfassung \\ $\nabla$}

Der Nachweis humaner Papillomviren (HPV) im Rahmen der Vorsorge und Behandlung des Zervixkarzinoms und insbesondere seiner Vorstufen hat in den vergangenen Jahren zunehmend an Bedeutung gewonnen. Die HPV-Bestimmung wird beispielsweise zur weiteren Abklärung auffälliger Pap-Abstriche oder in der Nachsorge nach Behandlung präinvasiver Veränderungen empfohlen. Mehrere randomisierte kontrollierte Studien konnten zudem eine Überlegenheit gegenüber einem reinen Zytologie-Screening zeigen. Die Typisierung der unterschiedlichen Hochrisiko-HPVTypen aus Abstrichproben hat dagegen erst in geringerem Maße Anwendung in der Praxis gefunden. Es zeigen sich jedoch große Unterschiede in der onkogenen Potenz und Relevanz der unterschiedlichen Genotypen. HPV 16 hat zahlenmäßig und auch prospektiv mit Abstand die höchste Bedeutung für die Entstehung zervikaler Neoplasien. Die Genotypisierung kann daher für eine bessere Risikostratifizierung HPV-positiver Frauen hilfreich sein.

\section{Procedures for HPV Testing and Genotyping}

After its approval by the US Food and Drug Administration (FDA) in 2003, the Hybrid Capture 2 test (hc2; Qiagen, Hilden, Germany) has been the standard test for the detection of HPV in clinical practice for almost 10 years. The test can detect $13 \mathrm{hrHPV}$ genotypes $(16,18,31,33,35,39,45$, $51,52,56,58,59$ und 68 ) and is based on the hybridisation of HPV DNA with HPV RNA. The DNA-RNA connections are marked with antibodies and detected using chemiluminescence. However, the test does not differentiate between individual HPV genotypes. Results are given as either hrHPV-positive or hrHPV-negative. The assay can 
also be used to detect low-risk HPV (lrHPV) genotypes. The advantage of the hc2 test is its long-standing and extensive use in clinical practice; the disadvantage is the potential for cross-reactivity with other, usually lrHPV genotypes, which can lead to false-positive results [1].

In the last decade numerous new hrHPV tests have come on the market based on DNA detection using polymerase chain reaction (PCR) assays. These tests are usually capable of detecting any of 14 hrHPV genotypes $(31,33,35,39,45,51,52,56,58,59,66$ und 68). Moreover, some offer the possibility of separately determining the individual hrHPV genotype. In general, the most commonly detected genotypes are HPV 16 and 18, and some manufacturers also offer tests which can detect other genotypes. In principle, it is possible to detect even very low amounts of virus DNA using PCR. Such highly sensitive detection methods, however, have no importance in routine clinical diagnostics as they often detect HPV infections with no clinical relevance (cf. $\odot$ Table 1). Most commonly available, commercial PCR-based tests have therefore adapted their detection thresholds accordingly. The disadvantage of PCR-based assays is the limited clinical experience, although numerous studies of these tests have been done in recent years $[1,2]$.

\section{HPV-based Screening Compared to Cytology}

Several recent large European randomised controlled studies were able to demonstrate the superiority of HPV-based cervical cancer screening compared to cytology - whether using HPV detection alone or in combination with cytology (cf. ๑ Table 2). However, it is important to consider the results with regard to their specificity and positive predictive value (PPV) as these are important parameters for feasible screening programmes.

Between 1997 and 2005, the extensive Swedish populationbased research programme Swedescreen evaluated 11 different screening algorithms based either on HPV tests alone, or on Pap tests alone, or on various combinations of HPV and Pap. In a subgroup of women aged 32-38 years from the Swedescreen collective, a 35\% increased sensitivity for the detection of CIN 3 and invasive carcinoma (CIN 3+) was demonstrated in the group which underwent "Pap and type-specific HPV persistence" double testing compared to cytology alone [3]. The positive predictive value was also comparable. But this screening strategy is expensive and time-consuming as twice as many tests are required to obtain these good screening results. Another algorithm used the HPV test as the initial test, followed by a cytology triage in HPV-positive women with subsequent testing for persistent HPV infections in Pap-negative women and compared this algorithm with the results of cytology alone. This algorithm achieved an increase in sensitivity of $30 \%$ for the detection of CIN 3 or invasive carcinoma (CIN 3+). Moreover, this differential diagnostic algorithm had a comparable positive predictive value (PPV) but the number of screening tests required only increased by $12 \%$ (from 6257 to 7019).

The Dutch POBASCAM study also demonstrated a higher sensitivity for combined screening compared to cytology alone [4]. Two screening phases were carried out with an interval of 5 years between phases. In the 1 st phase $24 \%$ more CIN $2+$ were detected in the group who underwent combined cytology and HPV tests compared to the group tested using cytology alone. In the 2nd phase, the CIN 3+ detection rate in the HPV-tested group was $28 \%$ lower and the rate of invasive cancers was $71 \%$ lower com-
Table 1 Definitions.

\begin{tabular}{|c|c|}
\hline Sensitivity & $\begin{array}{l}\text { Number of persons with disease (in this case, women } \\
\text { with high-grade CIN), who were correctly identified by } \\
\text { the test method used (HPV test or cytological smear) } \\
\text { as having disease compared to the overall number of } \\
\text { persons with disease. }\end{array}$ \\
\hline Specificity & $\begin{array}{l}\text { Number of healthy persons who were correctly identi- } \\
\text { fied by the test method as free from disease compared } \\
\text { to the overall number of healthy persons in the study. }\end{array}$ \\
\hline \multicolumn{2}{|c|}{$\begin{array}{l}\text { A test with maximum sensitivity would detect all persons with disease: } \\
\text { the test sensitivity would be } 100 \% \text {. However, such a test usually has a low } \\
\text { specificity, i.e. many false-positive results. }\end{array}$} \\
\hline $\begin{array}{l}\text { Positive predic- } \\
\text { tive value (PPV): }\end{array}$ & $\begin{array}{l}\text { Number of persons with de facto disease out of all per- } \\
\text { sons with positive test results. In younger women, HPV } \\
\text { test has a relatively low PPV for high-grade CIN, as many } \\
\text { transient HPV infections may occur in this age group } \\
\text { without dysplastic changes of the cervix. }\end{array}$ \\
\hline $\begin{array}{l}\text { Negative predic- } \\
\text { tive value (NPV): }\end{array}$ & $\begin{array}{l}\text { Number of de facto healthy persons of all persons with } \\
\text { negative test results. The NPV of a correctly performed } \\
\text { HPV test is very high as almost no cervical cancers or } \\
\text { high-grade CIN lesions are HPV-negative; if the smear } \\
\text { is HPV-negative, any such changes can be excluded with } \\
\text { a high degree of probability. }\end{array}$ \\
\hline $\begin{array}{l}\text { Cytology triage } \\
\text { after positive } \\
\text { HPV test: }\end{array}$ & $\begin{array}{l}\text { All women first tested for HPV. HPV-positive women } \\
\text { additionally investigated by conventional Pap smear or } \\
\text { liquid-based cytology. Women with abnormal cytology } \\
\text { are investigated further, usually using colposcopy, while } \\
\text { women with normal cytology are investigated again by } \\
\text { HPV test and poss. cytology after a specified interval } \\
\text { of time has passed. }\end{array}$ \\
\hline
\end{tabular}

pared to the cytology group despite comparable overall numbers of CIN 3+ in both groups. These data show that combined screening can result in earlier detection of clinically relevant intraepithelial neoplasias.

The Italian NTCC study showed similar results [5]. A total of 47000 women were randomised into two groups, with the $1 \mathrm{st}$ group screened by cytology alone and the 2nd group screened using cytology and HPV test (later in the study, no cytology was done in later recruits to the 2 nd cohort). The detection of abnormalities was followed by the appropriate therapy. After 2 years, both groups again had cytological screening. In the 1st screening, a similar number of invasive cervical carcinomas had been detected in both groups ( $\bullet$ Fig. 1 ). In the 2nd screening, no further cancers were found in the group screened using HPV test, while 9 more cancers were detected in the cytology group. The initial cytology findings in all 9 cases with carcinomas found at the 2nd screening had been normal.

With regard to CIN 2 and CIN 3 ( $\bullet$ Fig. 2), almost twice as many cases were found in the HPV group in the 1st round of screening and approximately half as many in the 2nd round compared to the cytology group. This led the authors to conclude that initial HPV screening results in better early detection of clinically relevant precancerous lesions. The detection of twice as many CIN 2 and CIN 3 with HPV test during the initial screening round meant that these lesions were treated in time and progression to more invasive cancers was prevented. It must be assumed that the precancerous lesions not detected during the 1st screening phase in the cytology group led to the 9 cancers found at the 2nd screening. However, the authors recommend that screening including HPV testing should only be done in women older than 35 years, followed by cytology triage in HPV-positive cases. 


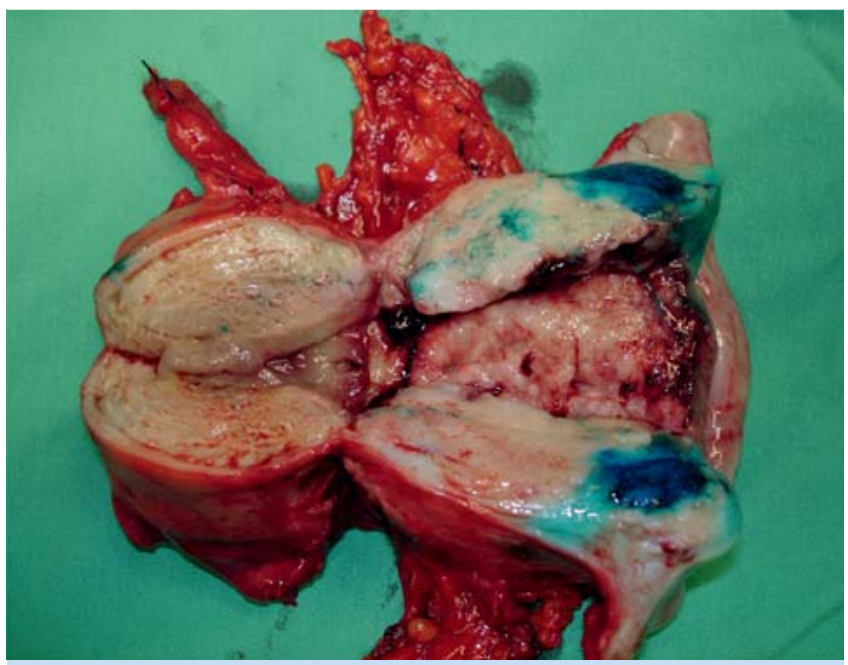

Fig. 1 Squamous cell carcinoma of the uterine cervix pT1b1, N0, G2 after radical endoscopic hysterectomy and combined blue dye/technetium 99m radiocolloid (intracervical) identification of sentinel lymph nodes.

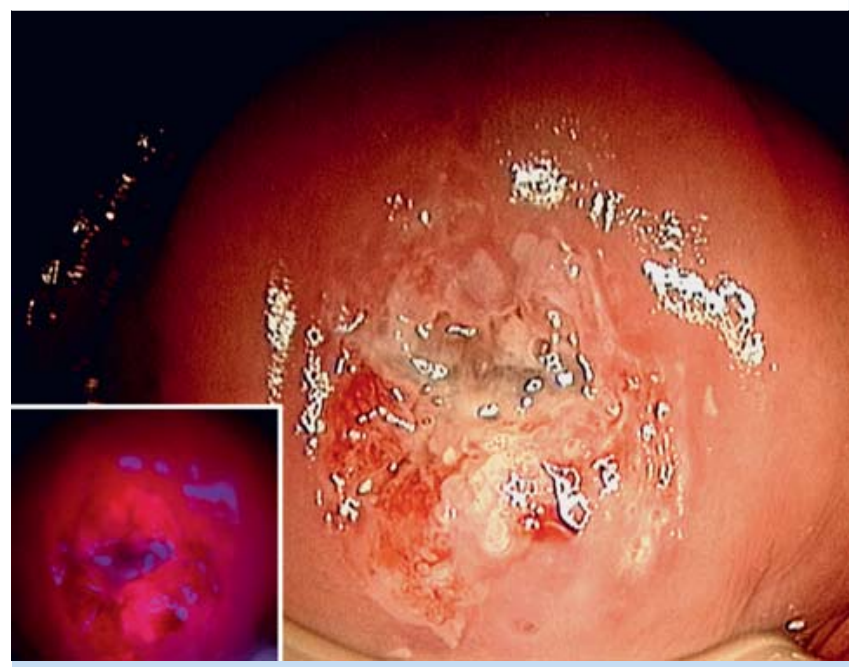

Fig. 2 Colposcopy of a CIN 2 lesion after application of $5 \%$ acetic acid. Insert shows diagnostic fluorescence imagíng of the same CIN 2 after the application of hexaminolevulinate.
In 2008, Dillner et al. investigated the 6-year risk to develop a CIN $3+$ lesion as a function of hrHPV status and cytology in a multinational cohort study [6]. No HPV genotyping was performed in this study. As expected, hrHPV-positive women with abnormal cytology had the highest risk with 34\%. In hrHPV-positive women with normal cytology the CIN $3+$ rate after 6 years was $10 \%$, while in the converse case (i.e., hrHPV negative, abnormal cytology) the incidence was only $2.7 \%$. Women with a negative hrHPV status at the beginning of the study showed a 6-year risk to develop CIN 3+ of only $0.27 \%$ - irrespective of their initial cytological findings. The authors therefore concluded that if the initial hrHPV result was negative, the screening interval could be extended to 6 years without additional risk for the women.

\section{Risk Potential for Different hrHPV Types \\ $\nabla$}

Numerous retrospective and a few prospective studies have shown clear differences between various hrHPV genotypes with regard to the risk of developing CIN or invasive cancer. In one of the largest retrospective studies of women with invasive cervical cancer performed worldwide, de Sanjose et al. were able to determine the HPV DNA in 85\% of the more than 10000 investigated cases [7]. HPV 16 was by far the most commonly found genotype with an incidence of $61 \%$, followed by HPV 18 (10\%) and HPV 45 (6\%). Moreover, the women in whom one of these 3 HPV genotypes was detected were approximately 4 years younger when the cancers were detected compared to women in whom other HPV genotypes were determined in their cancer cells.

An American study of 1213 women with carcinoma in situ (CIN 3) and 808 women with invasive cervical cancer detected HPV DNA in $97.1 \%$ of CIN 3 lesions and in $91.0 \%$ of invasive carcinomas [8]. Once again, HPV 16 was the most common genotype with an incidence of 56.3 and $53.2 \%$, respectively. In cases with CIN 3 this was followed by HPV 31 (12.6\%), HPV 33 (8.0\%) and HPV 18 (5.9\%), and HPV 18 (13.1\%) and HPV 45 (6.1\%) were also detected in women with invasive cancer. This study also found a significant difference in age between women with invasive cancer and positive for HPV 16 or HPV 18 compared to women with other HPV genotypes (48.1 and 45.9 years respectively vs. 52.3 years). HPV 16 also played the most important role in direct precancerous lesions. In the American ALTS study, HPV DNA was detected in $98.8 \%$ of the 608 investigated women with CIN 3 [9]. 59.9\% of cases were HPV 16 positive. In this study, HPV 18 (13.2\%) was only the fifth most common genotype after HPV 31 (18.1\%), HPV 52 (14.8\%) and HPV 51 (14.0\%). Here again, precancerous lesions caused by HPV 16 occurred in younger women (23.5 years) compared to lesions caused by other genotypes (25 years). Interestingly, HPV 16 positive CIN 3 lesions were more common in women who smoked and less common in multiparous women. In 2005 Khan et al. showed in a prospective type-specific HPV cohort study of more than 20000 women without high-grade cytology that HPV 16 and HPV 18 positive women had a significantly increased risk of developing CIN 3+ [10]. For women who were HPV 16 positive at the beginning of the study the cumulative 10-year incidence rate for CIN 3+ was 17\%, and for HPV 18 positive women it was $14 \%$. In comparison, the risk for other hrHPV genotypes was 3\%, and for hrHPV-negative women it was only $1 \%$. This risk distribution was even more significant for women above the age of 30 . In HPV 16 positive women aged $>30$ years the 10 -year incidence rate for CIN $3+$ was $20 \%$, while HPV 18 positive women aged $>30$ years had a 10 -year incidence rate of $15 \%$.

The higher sensitivity of HPV tests for screening compared to conventional cytology was also clearly demonstrated. The authors compared women above the age of 30 with abnormal cytology irrespective of their HPV status (LSIL: low grade squamous intraepithelial lesions; women with high-grade cytology were not included in the study) with women who were HPV 16 positive or HPV 18 positive at the beginning of the study. The 10-year incidence for CIN 3+ in the abnormal cytology group was only $11 \%$ compared to $20 \%$ and $15 \%$ respectively in the HPV 16 and HPV 18 groups. Moreover, even women with normal cytology who were HPV 16 or HPV 18 positive were shown to have an increased risk for developing CIN 3+.

Based on these data the authors advocate that type-specific HPV 16 and HPV 18 testing be done when screening women above the 
Table 2 Overview of randomised controlled studies on cervical cancer screening by HPV detection.

\begin{tabular}{|c|c|c|c|c|c|c|c|c|c|}
\hline \multirow[t]{2}{*}{ Study } & \multirow[t]{2}{*}{$\begin{array}{l}\text { Coun- } \\
\text { try }\end{array}$} & \multirow[t]{2}{*}{$\begin{array}{l}\text { No. of } \\
\text { partici- } \\
\text { pants }\end{array}$} & \multirow[t]{2}{*}{$\begin{array}{l}\text { Age } \\
\text { (years) }\end{array}$} & \multicolumn{2}{|c|}{$\begin{array}{l}\text { Screening } \\
\text { method used }\end{array}$} & \multirow[t]{2}{*}{ Sequence } & \multirow[t]{2}{*}{$\begin{array}{l}\text { Colpos- } \\
\text { copy rate }\end{array}$} & \multirow[t]{2}{*}{$\begin{array}{l}\text { Follow- } \\
\text { up } \\
\text { (years) }\end{array}$} & \multirow[t]{2}{*}{ Results and comments } \\
\hline & & & & $\begin{array}{l}\text { HPV } \\
\text { group }\end{array}$ & & & & & \\
\hline $\begin{array}{l}\text { ARTISTIC } \\
\text { [15] }\end{array}$ & UK & 24510 & $20-64$ & $\begin{array}{l}\text { hC2 }+ \\
\text { LBC }\end{array}$ & LBC & $\begin{array}{l}2 \text { investigations } \\
\text { with an interval } \\
\text { of } 2 \text { years }\end{array}$ & n.s. & 4.8 & $\begin{array}{l}\text { 1st round: no differences } \\
\text { 2nd round: signif. fewer CIN 2+/CIN } 3 \\
+ \text { in HPV group, but small absolute } \\
\text { difference }\end{array}$ \\
\hline $\begin{array}{l}\text { Finland } \\
\text { [16] }\end{array}$ & Finland & 58076 & $30-60$ & $\begin{array}{l}\text { hc2 }+ \\
\text { Pap } \\
\text { triage }\end{array}$ & Pap & $\begin{array}{l}1 \text { investigation, } \\
\text { follow-up via } \\
\text { cancer registry }\end{array}$ & $\begin{array}{l}\text { hc2: } 7.2 \% \\
\text { Pap: } 6.6 \%\end{array}$ & 3.3 & $\begin{array}{l}\text { 1st round: } 3 \text { more CIN } 2+\text { and CIN } 3+ \\
\text { in HPV group } \\
\text { After } 3.3 \text { Y: HPV: } 11 \text { ICC/AIS vs. Pap: } \\
6 \text { ICC/AIS }\end{array}$ \\
\hline $\begin{array}{l}\text { NTCC } \\
\text { phase } 1 \\
{[5]}\end{array}$ & Italy & 45174 & $25-60$ & $\begin{array}{l}\text { hC2 }+ \\
\text { LBC }\end{array}$ & Pap & $\begin{array}{l}2 \text { investigations } \\
\text { with an interval } \\
\text { of } 3 \text { years }\end{array}$ & $\begin{array}{l}\text { hc2: } 9.4 \% \\
\text { Pap: } 3.0 \%\end{array}$ & 3.5 & $\begin{array}{l}\text { 1st round: } 2 \times \text { more } \mathrm{CIN} 2+\text { and CIN } 3 \\
\text { + in HPV group; similar number of ICC } \\
\text { 2nd round: HPV: } 0 \text { ICC vs. Pap: } 9 \text { ICC } \\
\text { ( } p=0.004) \\
\text { Age } 35-60 \text { yrs: } 1 \text { st round HPV: twice } \\
\text { the number of CIN } 2 \& 3 \text {; } 2 \text { nd round } \\
\text { HPV: } c \text {. half the number of CIN } 2 \& 3\end{array}$ \\
\hline $\begin{array}{l}\text { NTCC } \\
\text { phase } 2 \\
{[5]}\end{array}$ & Italy & 49196 & $25-60$ & hc2 & Pap & $\begin{array}{l}2 \text { investigations } \\
\text { with an interval } \\
\text { of } 3 \text { years }\end{array}$ & & & \\
\hline $\begin{array}{l}\text { POBAS- } \\
\text { CAM } \\
{[4,17,18]}\end{array}$ & $\begin{array}{l}\text { Nether- } \\
\text { lands }\end{array}$ & $\begin{array}{l}44105 \\
\text { (1st } \\
\text { round) } \\
33499 \\
\text { (2nd } \\
\text { round) }\end{array}$ & $29-56$ & $\begin{array}{l}\text { PCR + } \\
\text { Pap }\end{array}$ & Pap & $\begin{array}{l}2 \text { investigations } \\
\text { with an interval } \\
\text { of } 5 \text { years }\end{array}$ & $\begin{array}{l}\text { PCR: } 2.3 \% \text {, } \\
1.3 \% \\
\text { Pap: } 1.3 \% \text {, } \\
1.9 \%\end{array}$ & 6.5 & $\begin{array}{l}\text { 1st round: } 24 \% \text { more CIN 2+ in HPV } \\
\text { group } \\
\text { 2nd round: } 28 \% \text { fewer CIN } 3+\text { and } \\
71 \% \text { fewer ICC in HPV group } \\
\rightarrow \text { with PCR earlier detection of clini- } \\
\text { cally relevant CIN 2+ }\end{array}$ \\
\hline $\begin{array}{l}\text { Swede- } \\
\text { screen [3] }\end{array}$ & $\begin{array}{l}\text { Swe- } \\
\text { den }\end{array}$ & 12527 & $32-38$ & $\begin{array}{l}\text { PCR + } \\
\text { Pap }\end{array}$ & Pap & $\begin{array}{l}2 \text { investigations } \\
\text { with an interval } \\
\text { of } 3 \text { years }\end{array}$ & PCR: $1.6 \%$ & 4.1 & $\begin{array}{l}\text { 1st round: } 51 \% \text { more CIN 2+ in HPV } \\
\text { group } \\
\text { 2nd round: } 42 \% \text { fewer CIN 2+ in HPV } \\
\text { group }\end{array}$ \\
\hline $\begin{array}{l}\text { India [19]( } \\
\text { developed } \\
\text { previous sc } \\
\text { programm }\end{array}$ & $\begin{array}{l}\text { der- } \\
\text { gion, no } \\
\text { ening }\end{array}$ & 131746 & $30-59$ & $\begin{array}{l}\text { single-r } \\
\text { hc2 vs. } \\
\text { with ace }\end{array}$ & $\begin{array}{l}\text { רd of s } \\
\text { vs. ce } \\
\text { acid }\end{array}$ & $\begin{array}{l}\text { ening: } \\
\text { cal inspection } \\
\text { standard care" }\end{array}$ & $\begin{array}{l}\text { hc2: } 1.3 \% \\
\text { Pap: } 4.9 \% \\
\text { insp.: } \\
10.8 \%\end{array}$ & 8 & $\begin{array}{l}\text { relative risk for the detection of ad- } \\
\text { vanced cervical cancer ( } \geq \mathrm{II} \text { ) and the } \\
\text { number of deaths from cancer } \\
\text { halved with HPV vs. control group } \\
\text { (not with Pap or cervical inspection) }\end{array}$ \\
\hline
\end{tabular}

hc2: Hybrid Capture 2 HPV test; PCR: HPV detection with PCR assay; LBC: liquid-based cytology; Pap: conventional cytology; vs.: versus; n. s.: not specified; ICC: invasive cervical cancer; AIS: adenocarcinoma in situ

age of 20, and recommend colposcopy if the result is positive. If the findings are positive for other hrHPV genotypes they consider re-screening after 1 year sufficient.

Another recently published follow-up investigation of the same study collective showed a very low cumulative probability of developing CIN 3+ in women with a negative HPV status [11]. The incidence for women under the age of 30 was $1.8 \%$, while for women above the age of 30 it was merely $0.7 \%$ over a follow-up period of more than 15 years. The increased risk for HPV 16 positive women to develop CIN 3+ was again confirmed in this study. Compared to other hrHPV genotypes, the risk in women aged more than 30 years was more than double (2.7-fold relative risk), and compared to HPV negativity it was more than 6 times as high (6.2-fold relative risk). To compare the independent validity of HPV testing with that of cytology, the authors calculated the respective relative risk of developing CIN 2+ after a positive compared to a negative hrHPV test ( 7.1 for age $<30$ years and 8.5 for $30+$ ) and with abnormal (ASC-US/LSIL) compared to normal cytology (NILM) (1.5 for women aged $<30$ years and 2.9 for women aged $30+$ ). This clearly shows the higher validity of positive HPV test results compared to abnormal cytology results.
Because of the very high negative predictive value (NPV) of a negative HPV test in this investigation, the authors concluded that for women above the age of 30 with a negative HPV test and normal cytology, re-examination after 3 years - as is currently the standard in the USA - may not be necessary that early.

A population-based prospective Danish cohort study started in 1991 came to similar conclusions [12]. Around 7500 women with normal cytology at the start of the study underwent 2 gynaecological investigations with Pap smears and hrHPV genotyping at an interval of 2 years between investigations. The start of the study was defined as the time of the second investigation. All citizens in Denmark have a personal identification number, and the country additionally has a national pathology database in which all cervical cytologies and histologies are entered. This allows such study collectives to be followed up with almost no dropouts and at a relatively low cost. The evaluation of study results was done in 2007 after a maximum follow-up of 13.4 years.

It was shown that one quarter (26\%) of the women who were HPV 16 positive at the 2 nd investigation developed a CIN 3+ lesion during the follow-up period. For HPV 18 the incidence was $15.4 \%$. The figures were much lower for other hrHPV genotypes 
(HPV 33: 12.8\%; HPV 31: 9.8\%; HPV 35: 9.1\%; HPV 58: 8.3\%; HPV 45: 6.4\%). For hrHPV-negative women the CIN 3+ risk after 12 years was $3.0 \%$.

Taking 2 cervical smears at an interval of 2 years allowed the authors to evaluate the impact of persistent HPV infection. HPV 16, $31,33,35,52$ and 58 had the highest prevalence at the beginning of the study, a higher rate of persistence and a higher potential, if they persisted, to lead to a CIN 3+ lesion. Thus, 29.4\% of HPV 16 infections were persistent, i.e. HPV 16 was detectable at both investigations, and $46 \%$ of women with persistent HPV 16 infection developed CIN 3+. Interestingly, the 12-year risk for CIN 3+ in women in whom hrHPV was detected at both investigations using hc2 was $19.3 \%$ irrespective of the HPV genotype, and thus similar to the risk reported for women in whom HPV 16 was detected once (17.3\%).

In 2011 in a subgroup analysis of the ATHENA HPV study, in women with ASCUS cytology (atypical squamous cells of undetermined significance) Stoler et al. found a clear correlation between their HPV 16 and/or HPV 18 positivity rate and a more severe grade of CIN [13]. The two HPV genotypes were found in only $8 \%$ of women without CIN, but in $18 \%$ of cases with CIN 1 , $44 \%$ of cases with CIN 2 and $61 \%$ of cases with CIN $3+$. The absolute risk for CIN $3+$ was $20 \%$ for HPV 16 positive women. Compared to HPV-negative women, the relative risk for CIN 3+ was 70.9 for HPV 16 positive women and 15.4 for HPV 18 positive women. The relative risk for 12 other hrHPV genotypes was only 15.7 in total. When HPV 16 was compared with these 12 other hrHPV genotypes, HPV 16 still had a relative risk of 4.5.

\section{Discussion}

$\nabla$

The studies presented here clearly show the potential for HPV tests in cervical cancer screening. On the one hand, a negative result, particularly in women above the age of 30, offers a high degree of certainty that they are unlikely to develop CIN 3+ within a period of several years. For these women, extending the intervals between screenings, as recommended by some authors, is certainly justified. In view of the pressure to reduce costs in healthcare today, this is additionally relevant.

The appropriate management of women who tested positive for hrHPV is more difficult. A differentiated assessment on a case-bycase basis which also takes account of cytology findings is necessary. HPV genotyping also offers advantages for the assessment of the individual risk of an HPV-positive woman to develop CIN 3+ in the future. In all of the studies cited here, HPV 16 was found to be the genotype with the highest oncogenic potential among the hrHPV genotypes. It was not merely that in most cases HPV type 16 was detected in women with CIN 3 or carcinoma; prospectively, infection with HPV 16 resulted more often in the development of an intraepithelial neoplasia than other hrHPV genotypes. The age at which HPV 16 was contracted was also lower than the age at which women were infected with other hrHPV genotypes. The studies did not come to any consistent conclusion with regard to other hrHPV genotypes, doubtlessly also due to regional differences. In addition to HPV 18, the most important genotype after HPV 16, HPV 31, 33 and 45 in particular appear to be associated with a slightly higher risk. In addition, HPV genotyping also allows the definitive identification of women with persistent infection, a significant risk factor for developing higher grade lesions.
In clinical practice this could mean that women positive for HPV 16 and possibly also women positive for HPV 18 could undergo colposcopy examination and be followed up more closely than women with other hrHPV genotypes. Nevertheless, it is important to keep in mind that the long-term risk of developing CIN 3+ is only $20-25 \%$, depending on the study, after the first-time detection of HPV 16 [10,12,13]. For three quarters of HPV 16 positive women this entails unnecessary additional investigations. However, if HPV 16 persists, the risk of developing a CIN 3+ lesion increases to almost 50\% [12]. The more intensive management of women positive for HPV 16 places a burden on patients and physicians and is obviously also accompanied by higher treatment costs. Whether these additional costs can be compensated for by the reduced number of screenings required by HPV-negative women remains to be seen.

When interpreting the cited studies it is also important to remember that the results obtained in some cases may not be easily transferred to the German early detection system, as other countries already use distinctly longer screening intervals in the setting of an organised screening programme. In the Dutch POBASCAM study, for example, the interval between 2 investigations was 5 years, while in the Italian NTCC study the interval was 2 years.

The data presented here may soon have practical consequences in the Netherlands. In May 2011, the Health Council of the Netherlands which advises the Dutch government revised its recommendations on cervical cancer screening. The new recommendations suggest carrying out initial HPV-based screening, with around 5 tests done over the lifetime of a woman: the first one at the age of 30 years, then at ages 35, 40, 50 and 60 years. HPVpositive women will be investigated further using cytology triage [14].

\section{Summary \\ $\nabla$}

In summary, it is clear that the inclusion of HPV testing in cervical cancer screening offers a high degree of certainty. For women who are HPV-negative, the intervals between investigations can be extended. HPV genotyping is currently being discussed with a view to a better risk stratification and identification of women at increased risk who will require more intensive monitoring.

\section{Conflict of Interest}

$\nabla$

M. Jentschke received a speaker's fee and travel costs from Abbott GmbH \& Co. KG, Wiesbaden.

\section{References}

1 Poljak M, Kocjan BJ. Commercially available assays for multiplex detection of alpha human papillomaviruses. Expert Rev Anti Infect Ther 2010; 8: 1139-1162

2 Meijer CJ, Berkhof J, Castle PE et al. Guidelines for human papillomavirus DNA test requirements for primary cervical cancer screening in women 30 years and older. Int I Cancer 2009; 124: 516-520

3 Naucler P, Ryd W, Tornberg S et al. Efficacy of HPV DNA testing with cytology triage and/or repeat HPV DNA testing in primary cervical cancer screening. J Natl Cancer Inst 2009; 101: 88-99

4 Bulkmans NW, Berkhof J, Rozendaal L et al. Human papillomavirus DNA testing for the detection of cervical intraepithelial neoplasia grade 3 and cancer: 5-year follow-up of a randomised controlled implementation trial. Lancet 2007; 370: 1764-1772 
5 Ronco G, Giorgi-Rossi P, Carozzi F et al. Efficacy of human papillomavirus testing for the detection of invasive cervical cancers and cervical intraepithelial neoplasia: a randomised controlled trial. Lancet Oncol 2010; 11: 249-257

6 Dillner J, Rebolj M, Birembaut P et al. Long term predictive values of cytology and human papillomavirus testing in cervical cancer screening: joint European cohort study. BMJ 2008; 337: a1754

7 de Sanjose S, Quint WG, Alemany L et al. Human papillomavirus genotype attribution in invasive cervical cancer: a retrospective cross-sectional worldwide study. Lancet Oncol 2010; 11: 1048-1056

8 Wheeler CM, Hunt WC, Joste NE et al. Human papillomavirus genotype distributions: implications for vaccination and cancer screening in the United States. J Natl Cancer Inst 2009; 101: 475-487

9 Castle PE, Schiffman M, Wheeler CM et al. Human papillomavirus genotypes in cervical intraepithelial neoplasia grade 3. Cancer Epidemiol Biomarkers Prev 2010; 19: 1675-1681

10 Khan MJ, Castle PE, Lorincz AT et al. The elevated 10-year risk of cervical precancer and cancer in women with human papillomavirus (HPV) type 16 or 18 and the possible utility of type-specific HPV testing in clinical practice. J Natl Cancer Inst 2005; 97: 1072-1079

11 Schiffman M, Glass AG, Wentzensen $N$ et al. A long-term prospective study of type-specific human papillomavirus infection and risk of cervical neoplasia among 20,000 women in the Portland Kaiser cohort study. Cancer Epidemiol Biomarkers Prev 2011; 20: 1398-1409

12 Kjaer SK, Frederiksen K, Munk C et al. Long-term absolute risk of cervical intraepithelial neoplasia grade 3 or worse following human papillomavirus infection: role of persistence. J Natl Cancer Inst 2010; 102: $1478-1488$
13 Stoler MH, Wright jr. TC, Sharma A et al. High-risk human papillomavirus testing in women with ASC-US cytology: results from the ATHENA HPV study. Am J Clin Pathol 2011; 135: 468-475

14 Health Council of the Netherlands. Population screening for cervical cancer. Publication no. 2011/07. ISBN 978-90-5549-841-3. The Hague: 2011

15 Kitchener HC, Almonte M, Gilham C et al. ARTISTIC: a randomised trial of human papillomavirus (HPV) testing in primary cervical screening. Health Technol Assess 2009; 13: 1-150, iii-iv

16 Anttila A, Kotaniemi-Talonen L, Leinonen $M$ et al. Rate of cervical cancer, severe intraepithelial neoplasia, and adenocarcinoma in situ in primary HPV DNA screening with cytology triage: randomised study within organised screening programme. BMJ 2010; 340: c1804

17 Bulkmans NW, Rozendaal L, Snijders PJ et al. POBASCAM, a populationbased randomized controlled trial for implementation of high-risk HPV testing in cervical screening: design, methods and baseline data of 44,102 women. Int J Cancer 2004; 110: 94-101

18 Rijkaart DC, Berkhof J, Rozendaal L et al. Human papillomavirus testing for the detection of high-grade cervical intraepithelial neoplasia and cancer: final results of the POBASCAM randomised controlled trial. Lancet Oncol 2012; 13: 78-88

19 Sankaranarayanan R, Nene BM, Shastri SS et al. HPV screening for cervical cancer in rural India. N Engl J Med 2009; 360: 1385-1394

Deutschsprachige Zusatzinformationen online abrufbar unter: www.thieme-connect.de/ejournals/toc/gebfra. 